\title{
Juvenile Hyaline Fibromatosis Management With a Diode Laser: A Rare Case Report
}

\author{
Reza Fekrazad ${ }^{1}$, Farzad Fazilat ${ }^{2}$, Katayoun AM Kalhori ${ }^{3}$, Neda Hakimiha ${ }^{4}$, Mehrdad Amirmoini ${ }^{5}$, Maryam \\ Nikhalat Jahromi ${ }^{*}$
}

${ }^{1}$ Radiation Sciences Research Center, Laser Research Center in Medical Sciences, AJA University of Medical Sciences, Tehran, Iran

${ }^{2}$ International Network for Photo Medicine and Photo Dynamic Therapy (INPMPDT), Universal Scientific Education and Research Network (USERN), Tehran, Iran

${ }^{3}$ Oral and Maxillofacial Pathologist, Iranian Medical Laser Association, Tehran, Iran

${ }^{4}$ Laser Research Center of Dentistry, Dentistry Research Institute, Tehran University of Medial Sciences, Tehran, Iran

${ }^{5}$ AJA University of Medical Sciences, Tehran, Iran

${ }^{6}$ Laser Application in Medical Sciences Research Center, Shahid Beheshti University of Medical Sciences, Tehran, Iran

*Correspondence to Maryam Nikhalat Jahromi, D.D.S; Laser Application in Medical Sciences Research Center, Shahid Behesht University of Medical Sciences, Tehran, Iran. Tel: +989121542803; Email:

maryam.nikhalat@gmail.com

Published online January 18, 2020

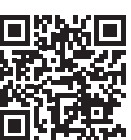

\begin{abstract}
Juvenile hyaline fibromatosis (JHF) is an unknown hereditary disorder with variable penetrance. The characterizations of this disease consist of different signs and symptoms such as multiple tumorous (tumor-like) muco-cutaneous proliferation, gingival hypertrophy, perianal lesions, articular contractures, and osteolytic lesions. A 3-year-old girl with numerous painless nodular masses on her gingival, ear and anal areas is presented in this case report. Based on characteristic histological features, the diagnosis of JHF was made. The patient underwent surgery following general anesthesia and the above areas were surgically operated with appropriate laser parameters, and the patient was able to eat and wash away after a day and was discharged with an antibiotic prescription after one day in the hospital and returned to normal after a week. The recurrence occurred in other areas a year later, especially in the cheek, the ears and the anal area. Therefore, this rare case is presented with recurrence.
\end{abstract}

Keywords: Juvenile hyaline fibromatosis (JHF); Diode laser; Chromosome 4q21 mutation.

\section{Introduction}

Juvenile hyaline fibromatosis (JHF) is an autosomal recessive disorder that has variable penetrance. The disease has been diagnosed with various tumour-like lesions with a muco-cutaneous source and also articular contractures, gingival hypertrophy, and osteolytic lesions. Patients present with perianal papillomatous lesions randomly. It has been suggested that JHF is a naturally progressive connective tissue disorder. ${ }^{1-4}$ The first report was made by Murray that called it "peculiar cases of molluscum fibrosum". In a study conducted in 1903, Whitfield and Robinson described that these cases did not belong to neurofibromatosis but should have been placed in a multiple fibromata category. ${ }^{5}$ After that, this disease was nearly forgotten until 1962 when Puretic et al named the condition "a unique form of mesenchymal dysplasia". JHF is so rare that only less than ninety cases have been reported globally. ${ }^{6,7}$ An autosomal recessive inheritance pattern has been reported for JHF. JHF is a moral disorder with an unknown etiology that appeared because of changes in the capillary morphogenesis protein 2 gene. The mutation of the CMG2 gene placed on chromosome $4 \mathrm{q} 21$. This gene is officially called "anthrax toxin receptor 2" (ANTXR2). ${ }^{8}$ The ANTXR2 gene is, therefore, uncharged of producing a specific protein and there is a poor understanding of the exact cellular role of the protein CMG2. However, being the anthrax toxin receptor is the role that CMG2 is best characterized., ${ }^{9,10}$ One of the genes that play a part in the three-dimensional collagen matrices is CMG2 which was recognized as an upregulated gene in endothelial cells. ${ }^{11}$ In mice, CMG 2 expressions were evident in endothelial cells in various body tissues including intestine, lungs, skin, and vascular endothelium and on smooth muscle cells. ${ }^{10}$ The basement membrane arrangement would get disturbed, enabling the hyaline substance to spill through and develop in different body parts including joints, bones and skin, prompting the development of gingival hyperplasia, skin papules, osteolytic lesions in bone and articular contractures. The tumor is not circumscribed adequately and is portrayed by an eosinophilic homogeneous ground substance which contains cells similar to a bland fibroblast with 
bounteous granular cytoplasm. ${ }^{12}$ The disease is clinically characterized by a series of findings including skin papules and joint contracture. Gingival hyperplasia is a common finding that can be sufficiently severe and interfering with feeding and causing poor oral hygiene, infection and dental caries. ${ }^{13}$ Histology can also confirm the diagnosis. ${ }^{14}$ The treatment is only based on esthetic and is intended to limit the orthopedic disability. ${ }^{14}$ The early surgical removal of skin lesions may help, but recurrences are common. ${ }^{15}$ In the oral field, laser systems and their applications have made huge progress. This rapid progress can be attributed to the fact that lasers allow soft tissue procedures with excellent hemostasis and field visibility to be carried out efficiently. Lasers offer maximum patient comfort after surgery. Thus laser therapy is the treatment of choice in this case. ${ }^{16,17}$

\section{Case Presentation}

A 3-year-old girl presented with various painless nodular masses on the face around her nose and chin. On examination, an anal papule and also gingival hyperplasia were noted (Figure 1).

The consistency of lesions was soft to firm and there was no tenderness in palpation. Lymphadenopathy and hepatosplenomegaly were not observed. Hematological and biochemical investigations were within normal limits. No history of consanguinity was present in the parents. In the first stage, few specimens were obtained from the anal region and cheek and transmitted for a pathological diagnosis. Microscopically, a poorly circumscribed lesion composed of spindle-shaped cells and benign oval in an abundant, homogenous, eosinophilic matrix

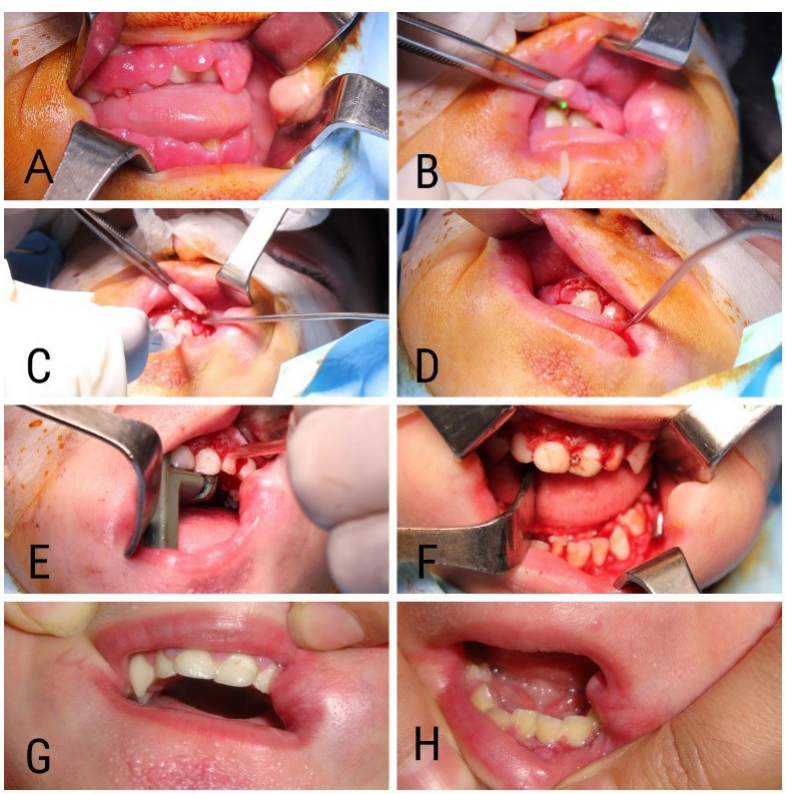

Figure 1. (A) the clinical examination before surgery; $(B, C, D, E, F)$ the application of the diode laser for removing oral lesions; $(G, H)$ the final result after 7-10 days of healing. was seen (Figure 2). There were no mitotic figures. The ground substance was negative for toluidine blue and was positive for PAS. Based on the clinical findings and histopathological slides, a diagnosis of JHF was made.

After obtaining consent from the parent, surgery was performed under general anesthesia. A diode laser (A.R.C - LASER Com, FOX - Germany) with a wavelength of 810 $\mathrm{nm}$, a power of 4 watts, a pulse width of 20 milliseconds, and an interval of 20 milliseconds by a 400-micron optical fiber was used by an expert person. Exophytic lesions were removed from the gum and anal areas (Figure 3) and the patient was discharged from the hospital with antibiotics and an anti-Septic prescription after a recovery day. The patient was able to eat. After a week, the situation was also very good, according to her parents' acknowledgment. However, the patient had a recurrence of lesions within one year and this time they appeared more in the cheek (Figure 4), the anal area and also the ear (Figure 5). The surgery was performed in a sensitive area in the vicinity of the cartilage of the ear, and the surgery was done according to the previous conditions and the same result was yielded and is currently under observation.

\section{Discussion}

JHF is considered rare mesenchymal dysplasia that is portrayed by numerous tumorous mucocutaneous lesions, gingival hypertrophy articular contractures, and osteolytic lesions. This disorder has a progressive nature, so it requires several surgical interventions and physiotherapy. ${ }^{1-4} \mathrm{JHF}$ is a kind of mesenchymal dysplasia that was initially named by Drescher et al and Murray J. as "peculiar cases of molluscum fibrosum".
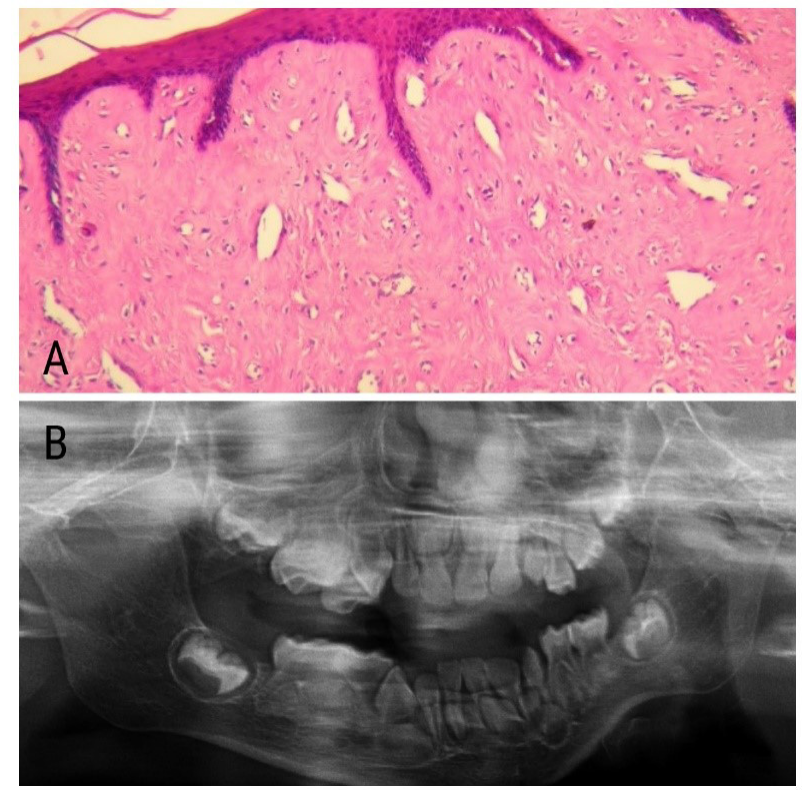

Figure 2. (A) the microscopical view of the lesion shows an amorphous hyaline matrix with fibroblast-like cells. (B) the panoramic image shows that there is no significant hard tissue disorder due to JHF. 


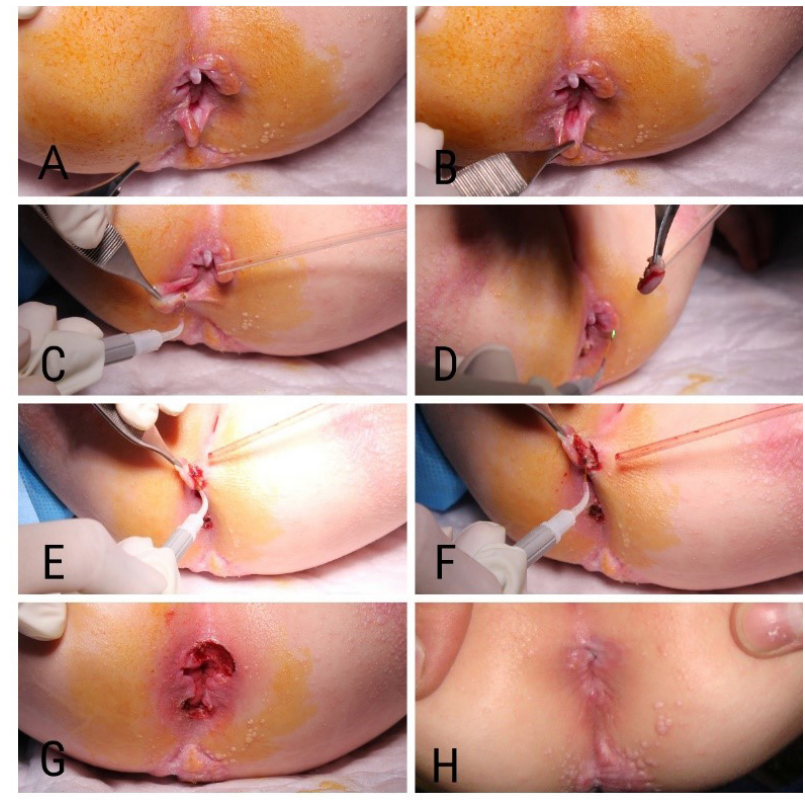

Figure 3. The JHF Lesion in the Anal Area Before and During Surgery and After Healing for 7-10 Days.
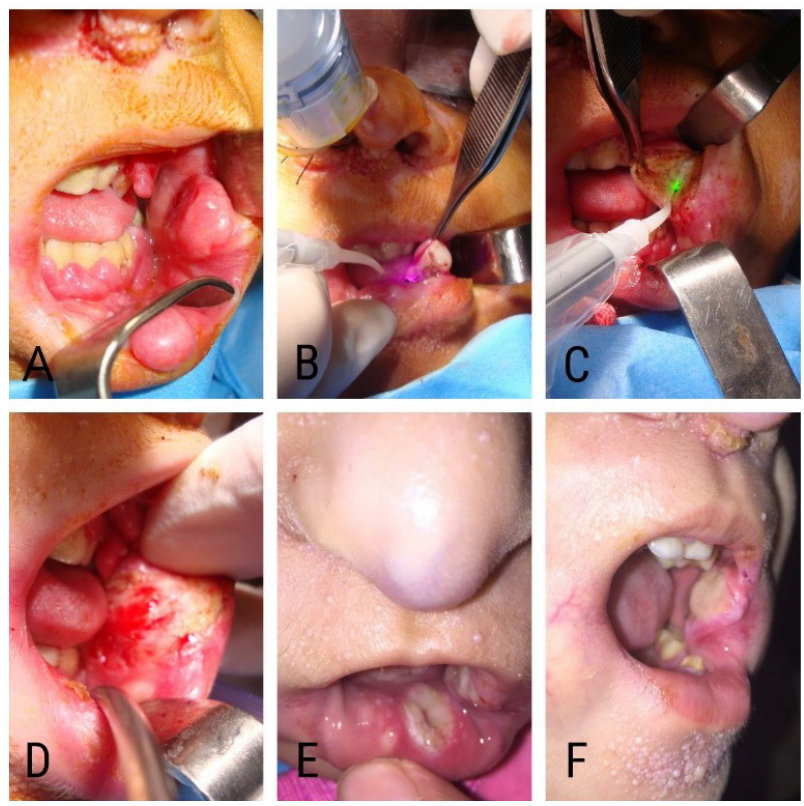

Figure 4. (A) The recurrent lesion within 1 year in the cheek. (B, C, D) the removal of the recurrent lesion by using a diode laser. $(E, F)$ the condition of the oral cavity after healing during 7-10 days.

alternative equivalent words include puretic syndrome, ${ }^{5}$ disseminated painful fibromatosis and fibromatosis hyalinica, and multiplex juvenilis. The diagnosis is based on histopathology. The histological features of the tumorlike lesions are characterized by tumor cells and the abundant ground substance. The tumor cells have oval nuclei and fine granular or vesicular cytoplasm, stained pale pink in HE staining. The cells are distributed in groups of a few to several in the ground substance. The ground substance is eosinophilic and homogeneous
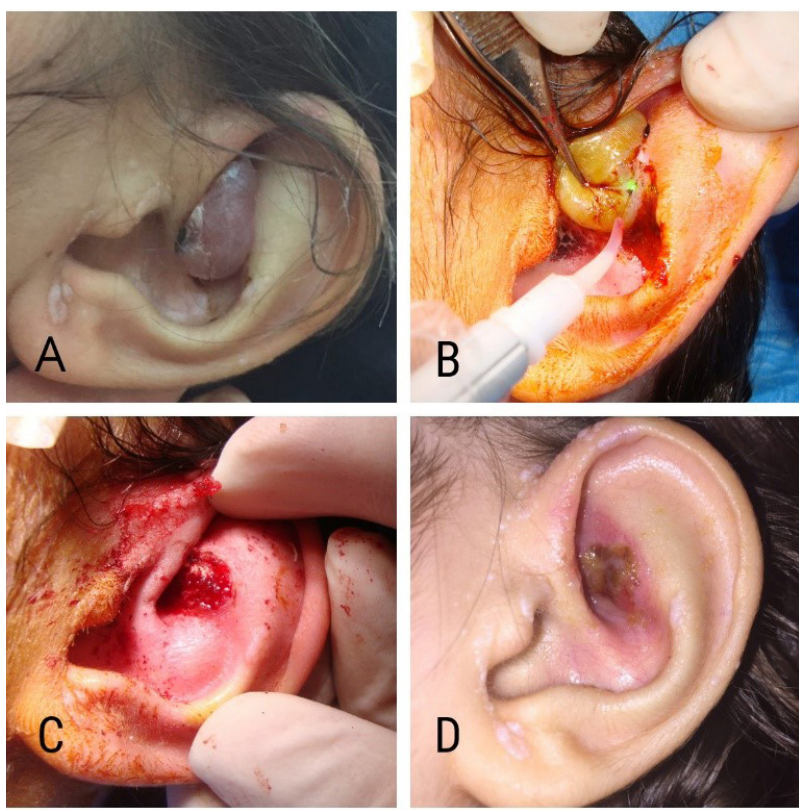

Figure 5. Ear Lesions in the Recurrent Stage and the Removal of Them by the Application of the Laser.

with some wavy filaments. ${ }^{12}$ The electron microscopic examination of tumor tissue showed that the ground substance is composed of delicate filaments. ${ }^{13}$

Infantile systemic hyalinosis, neurofibromatosis, gingival fibromatosis, congenital generalized fibromatosis, lipoid proteinosis and Winchester syndrome ${ }^{3}$ are placed in differential diagnosis with JHF, although the histological and clinical and immune histochemical findings exclude them.

No particular treatment is accessible for JHF. The treatment is only based on the preserve aesthetic of patients and its aim is to restrain the orthopedic disability. Early tumorectomy, intralesional systemic steroids, capsulotomy, partial gingivectomy, and physiotherapy are required to restrict flexion. Contractures would improve the situation of these patients; however, many cases have recurrences. ${ }^{18,19}$

The diode laser (810-1064 nm) has become very popular in general dentistry because of its small size, low cost, fiber optic delivery and ease of use for minor surgery of oral soft tissue. The advantages of laser surgery are relatively hemostasis and outstanding field visibility, minimal swelling, scarring and coagulation, no need for suturing, reduction in surgical time, and less or no postoperative surgical pain and edema. Patients undergoing diode laser surgery in the oral cavity seem to have less pain. In addition, less risk of edema and the dressing layer of denatured protein enhance healing with less risk of secondary infection. . $^{6,17,20-22}$

\section{Conclusion}

The diagnosis of JHF was made by clinical and histopathological solidarity. The precise and early 
diagnosis of this rare disease is very important so that no additional therapies are prescribed for them, and it is recommended that conservative treatment methods such as a surgical laser performed by a skilled person should be considered as alternative therapies for these patients. We recommend further studies in the future possibly with other methods in the hope that we can help these people to improve the quality of their lives.

\section{Ethical Considerations}

A consent form was obtained from the patient and the patient was also aware of all stages of treatment.

\section{Conflict of Interests}

The authors declare no conflict of interest.

\section{References}

1. Haleem A, Al-Hindi HN, Juboury MA, Husseini HA, Ajlan AA. Juvenile hyaline fibromatosis: Morphologic, immunohistochemical and ultrastructural study of three siblings. Am J Dermatopathol. 2002;24(3):218-24. doi: 10.1097/00000372-200206000-00006.

2. Brandao FV, Silva CMR, Gontijo B, Guedes ACM. Juvenile hyaline fibromatosis and infantile systemic hyalinosis. Case for diagnosis. An Bras Dermatol. 2009; 84(6): 677-9. doi: 10.1590/s0365-05962009000600017.

3. Nakipoglu GF, Dogan A, Dogan Aslan M, Ozgirgin N. Juvenile hyaline fibromatosis: case presentation (the rehabilitation of three siblings). Turk J Med Sci. 2004;34:6771.

4. Nischal KC, Sachdev D, Kharkar V, Mahajan S. Juvenile hyaline fibromatosis. J Postgrad Med. 2004;50(2):125-6.

5. Basak S, Rajurkar MN. Molluscum contagiosum-An update. Indian Med Gaz. 2013;147(7):276-8.

6. Park KT, Chang DY, Sung MW Juvenile hyaline fibromatosis. Clin Exp Otorhinolaryngol. 2010;3(2):102106. doi: 10.3342/ceo.2010.3.2.102.

7. Uslu H, Bal N, Guzeldemir E, Pektas ZO. Three siblings with juvenile hyaline fibromatosis. J Oral Pathol Med. 2007;36(2):123-5. doi: 10.1111/j.1600-0714.2007.00475.x.

8. Rahman N, Dunstan M, Teare MD, Hanks S, Edkins SJ, Hughes J, et al. The gene for juvenile hyaline fibromatosis maps to chromosome 4q21. Am J Hum Genet. 2002;71(4): 975-980. doi: 10.1086/342776.

9. Deuquet J, Lausch E, Guex N, Abrami L, Salvi S, Lakkaraju A, et al. Hyaline fibromatosis syndrome inducing mutations in the ectodomain of anthrax toxin receptor 2 can be rescued by proteasome inhibitors. EMBO Mol Med. 2011;3(4):208-221. doi: 10.1002/emmm.201100124.

10. Abrami L, Leppla SH, van der Goot FG: Receptor palmitoylation and ubiquitination regulate anthrax toxin endocytosis. J Cell Biol. 2006;172(2):309-20. doi: 10.1083/ jcb.200507067.

11. Liu S, Crown D, Miller-Randolph S, Moayeri M, Wang $\mathrm{H}, \mathrm{Hu} \mathrm{H}$, et al. Capillary morphogenesis protein-2 is the major receptor mediating lethality of anthrax toxin in vivo. Proc Natl Acad Sci U S A. 2009;106(30):12424-29. doi: 10.1073/pnas.0905409106.

12. Kitano Y. Junenile hyaline fibromatosis. Arch Dermatol. 1976;112(1): 86-88. doi: 10.1001/archderm.112.1.86.

13. Yayli S, Uncu S, Alpay K, Yildiz K, Cimsit G, Bahadir S. A case of juvenile hyaline fibromatosis. J Dermatol. 2006;33(4):260-64. doi: 10.1111/j.1346-8138.2006.00063.x.

14. Krishnamurthy J, Dalal BS, Sunita, Gubbanna MV. Juvenile hyaline fibromatosis. Ind J Dermatol. 2011;56(6):731-3. doi: 10.4103/0019-5154.91840.

15. Tehranchinia Z, Rahimi H. Juvenile hyaline fibromatosis in two siblings. Eur J Dermatol. 2010;20(5):631-2. doi: 10.1684/ejd.2010.0993.

16. Mathur E, Sareen M, Dhaka P, Baghla P. Diodelaser excision of oral benign lesions. J Lasers Med Sci. 2015;6(3):129-32. doi: $10.15171 / \mathrm{jlms} .2015 .07$

17. Coluzzi DJ. Fundamentals of dental lasers: science and Instruments. Dent Clin North Am. 2004;48(4):751-70. doi: 10.1016/j.cden.2004.05.003.

18. Kitano Y, Horiki M, Aoki T, Sagami S. Two cases of juvenile hyaline fibromatosis: some histological electron microscopic, and tissue culture observations. Arch Dermatol. 1972;106(6):877-83. doi: 10.1001/ archderm.106.6.877

19. Raja K, Khan MA, Mubarak M, Abbas Z, Luck NH, Hassan SM. Three years old child with juvenile hyaline fibromatosis presenting with rectal bleeding. J Pak Med Assoc. 2013;63(3):396-8.

20. Fekrazad R, Chiniforush N, Kalhori K. All done procedure by laser in free gingival graft treatment: A case series study. J Cosmet Laser Ther. 2019;21(1):4-10. doi: 10.1080/14764172.2017.1418518

21. Fekrazad R, Nokhbatolfoghahaei H, Khoei F, Kalhori K. Pyogenic granuloma: Surgical treatment with Er:YAG laser. J Lasers Med Sci. 2014;5(4):199-205.

22. Fekrazad R, Kalhori KAM, Chiniforush N. Defocused irradiation mode of diode laser for conservative treatment of oral hemangioma. J Lasers Med Sci. 2013;4(3):147-50. 